Laura P. Forsythe, Erin E. Kent, and Julia H. Rowland, National Cancer Institute, National Institutes of Health, Bethesda, MD; Laura P. Forsythe, Patient-Centered Outcomes Research Institute, Washington, DC; Kathryn E. Weaver, Wake Forest School of Medicine, Winston-Salem, NC; and Natasha Buchanan, Nikki A. Hawkins, Juan L. Rodriguez, and A. Blythe Ryerson, Centers for Disease Control and Prevention, Atlanta, GA

Published online ahead of print at www.jco.org on April 22, 2013.

Supported by Contract No. HHSN 261201100189P from the National

Cancer Institute, National Institutes of Health. Two authors were supported by the Cancer Prevention Fellowship Program (L.P.F. and E.E.K.)

Disclaimer: Findings and conclusions in this report are those of the authors and do not necessarily represent the official position of the National Cancer Institute, the Centers for Disease Control and Prevention, or the Patient-Centered Outcomes Research Institute.

Authors' disclosures of potential conflicts of interest and author contributions are found at the end of this article.

Corresponding author: Laura $\mathrm{P}$ Forsythe, PhD, MPH, Patient-Centered Outcomes Research Institute, 1828 L St NW, Suite 900, Washington, DC 20036; e-mail: Iforsythe@pcori.org. (c) 2013 by American Society of Clinica Oncology

0732-183X/13/3116w-1961w/\$20.00 DOI: 10.1200/JCO.2012.46.2101

\title{
Receipt of Psychosocial Care Among Cancer Survivors in the United States
}

Laura P. Forsythe, Erin E. Kent, Kathryn E. Weaver, Natasha Buchanan, Nikki A. Hawkins, Juan L. Rodriguez, A. Blythe Ryerson, and Julia H. Rowland

See accompanying editorial on page 1920

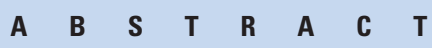

\section{Purpose}

Given the importance of psychosocial care for cancer survivors, this study used population-based data to characterize survivors who reported a discussion with health care provider(s) about the psychosocial effects of cancer and who reported using professional counseling or support groups (PCSG) and tested associations between receipt of psychosocial care and satisfaction with care.

\section{Patients and Methods}

We examined survivors of adult cancers from the 2010 National Health Interview Survey $(\mathrm{N}=$ 1,777). Multivariable logistic regression models examined factors associated with receipt of and satisfaction with psychosocial care.

\section{Results}

Most survivors (55.1\%) reported neither provider discussions nor use of PCSG; $31.4 \%$ reported provider discussion only, 4.4\% reported use of PCSG only, and 8.9\% reported both. Non-Hispanic blacks ( $v$ non-Hispanic whites), married survivors, survivors of breast cancer ( $v$ prostate or less prevalent cancers), those treated with chemotherapy, and survivors reporting past research study/clinical trial participation were more likely to report provider discussion(s) $(P<.01)$. Hispanics ( $v$ non-Hispanic whites), survivors age 40 to 49 years ( $v \leq 39$ years), survivors of breast cancer ( $v$ melanoma or less prevalent cancers), those diagnosed $\leq 1$ year ago ( $v>5$ years ago), survivors treated with radiation, and past research participants were more likely to report use of PCSG $(P<$.05). Survivors reporting any psychosocial care were more likely to be "very satisfied" with how their needs were met $(P<.001)$.

\section{Conclusion}

Many survivors do not report a discussion with providers about the psychosocial effects of cancer, which reflects a missed opportunity to connect survivors to psychosocial services. These data can benchmark the success of efforts to improve access to cancer-related psychosocial care.

\section{J Clin Oncol 31:1961-1969. (C) 2013 by American Society of Clinical Oncology}

\section{INTRODUCTION}

Cancer survivors commonly report psychological distress $^{1,2}$ and impaired social functioning ${ }^{3}$ which, although adversely associated with quality of life, ${ }^{2,4-10}$ health behaviors, ${ }^{11-15}$ and survival, ${ }^{16-20}$ often go unrecognized or undertreated. ${ }^{21-23}$ The Institute of Medicine's (IOM's) seminal 2008 report Cancer Care for the Whole Patient: Meeting Psychosocial Health Needs brought national attention to the importance of addressing psychosocial needs as part of quality cancer care. The report suggested that achieving this goal would require effective communication between patients and health care providers about psychosocial needs, identifying each survivor's unique needs, and connecting survivors with appropriate medical and/or supportive care services. ${ }^{24}$

Little is known on a population level about whether psychosocial care in practice is provided according to IOM recommendations. Factors associated with discussions between survivors and providers regarding how cancer affects emotions and relationships are understudied ${ }^{25}$ relative to research on the use of psychosocial services including professional counseling or support groups (PCSG). PCSG participation in the United States has been relatively static at approximately $14 \%$ over the last 20 years (Buchanan et al, submitted for publication). ${ }^{26}$ Breast cancer survivors and survivors within 5 years of diagnosis are historically more likely to use PCSG, ${ }^{26}$ but use has not been examined since the 
Table 1. Characteristics of Survivors of Adult Cancers in the United States $(\mathrm{N}=1,777)$

\begin{tabular}{|c|c|c|c|}
\hline Characteristic & $\begin{array}{l}\text { No. of } \\
\text { Patients }\end{array}$ & $\begin{array}{l}\text { Weighted } \\
\%\end{array}$ & $95 \% \mathrm{Cl}$ \\
\hline \multicolumn{4}{|l|}{$\begin{array}{l}\text { Age at most recent cancer diagnosis, } \\
\text { years }\end{array}$} \\
\hline$\leq 39$ & 319 & 18.7 & 16.4 to 21.0 \\
\hline $40-49$ & 295 & 16.5 & 14.6 to 18.4 \\
\hline $50-64$ & 588 & 33.8 & 31.1 to 36.6 \\
\hline$\geq 65^{*}$ & 506 & 27.4 & 24.9 to 29.9 \\
\hline Missing & 69 & 3.5 & 2.5 to 4.5 \\
\hline \multicolumn{4}{|l|}{ Sex } \\
\hline Male & 668 & 42.2 & 39.5 to 45.0 \\
\hline Female & 1,109 & 57.8 & 55.0 to 60.5 \\
\hline \multicolumn{4}{|l|}{ Race/ethnicity } \\
\hline Non-Hispanic white & 1,303 & 83.0 & 81.3 to 84.7 \\
\hline Non-Hispanic black & 242 & 8.3 & 7.1 to 9.5 \\
\hline Hispanic & 164 & 5.9 & 4.9 to 7.0 \\
\hline Other & 68 & 2.8 & 1.9 to 3.6 \\
\hline \multicolumn{4}{|l|}{ Marital status } \\
\hline Married/living as married & 861 & 63.5 & 61.0 to 65.9 \\
\hline $\begin{array}{l}\text { Never married/widowed/divorced/ } \\
\text { separated }\end{array}$ & 915 & 36.5 & 34.0 to 39.0 \\
\hline Missing & 1 & & \\
\hline \multicolumn{4}{|l|}{ Education } \\
\hline$<$ High school & 298 & 13.6 & 11.7 to 15.4 \\
\hline High school or GED & 485 & 28.7 & 26.1 to 31.2 \\
\hline Some college or associates degree & 525 & 30.1 & 27.4 to 32.8 \\
\hline Bachelor's degree or higher & 459 & 27.3 & 24.4 to 30.1 \\
\hline Missing & 10 & 0.4 & 0.1 to 0.7 \\
\hline
\end{tabular}

Poverty status, \% of Federal Poverty Levelt

$<100$

100-199

200-399

$\geq 400$

Health insurance status

Yes

No

Unknown

Region

Northeast

Midwest

South

West

Cancer site (most recent diagnosis)

Breast

Prostate

Melanoma

Cervical

Colorectal

Hematologic

Short-survival cancersł

Other cancer§

Unknownף

\section{6}

411.8

560.2

572.4

20.5

7.3 to 10.2

-18.5 to 22.7

$\begin{array}{lll}560.2 & 33.1 & 30.4 \text { to } 35.9 \\ 572.4 & 37.8 & 34.9 \text { to } 40.7\end{array}$

$1,369 \quad 77.7 \quad 75.4$ to 80.0

$\begin{array}{lll}145 & 7.0 & 5.7 \text { to } 8.3\end{array}$

$263 \quad 15.3 \quad 13.2$ to 17.4

Recurrence or multiple cancers

$\begin{array}{lrrr}\text { No } & 1,304 & 72.5 & 70.2 \text { to } 74.8 \\ \text { Yes } & 322 & 18.8 & 17.0 \text { to } 20.7 \\ \text { Missing } & 151 & 8.6 & 7.1 \text { to } 10.2\end{array}$

Time since most recent cancer diagnosis, years

$\begin{array}{crrc}<1 & 127 & 6.9 & 5.6 \text { to } 8.3 \\ 1-5 & 639 & 38.0 & 35.3 \text { to } 40.7 \\ & \text { (continued in next column) } & \end{array}$

Table 1. Characteristics of Survivors of Adult Cancers in the United States $(\mathrm{N}=1,777)$ (continued)

\begin{tabular}{|c|c|c|c|}
\hline Characteristic & $\begin{array}{c}\text { No. of } \\
\text { Patients }\end{array}$ & $\begin{array}{c}\text { Weighted } \\
\%\end{array}$ & $95 \% \mathrm{Cl}$ \\
\hline $6-9$ & 266 & 14.9 & 12.6 to 17.1 \\
\hline$\geq 10$ & 676 & 36.7 & 34.0 to 39.4 \\
\hline Missing & 69 & 3.5 & 2.5 to 4.5 \\
\hline \multicolumn{4}{|l|}{ Treatment timing } \\
\hline No recent treatment & 1350 & 75.6 & 73.3 to 77.9 \\
\hline Recent treatment (last 12 months) & 153 & 8.7 & 7.2 to 10.3 \\
\hline Current treatment & 109 & 5.9 & 4.6 to 7.2 \\
\hline Missing & 165 & 9.8 & 8.1 to 11.4 \\
\hline \multicolumn{4}{|l|}{ Surgery } \\
\hline No & 490 & 27.3 & 24.8 to 29.8 \\
\hline Yes & 1,115 & 62.6 & 59.7 to 65.4 \\
\hline Missing & 172 & 10.1 & 8.4 to 11.8 \\
\hline \multicolumn{4}{|l|}{ Chemotherapy } \\
\hline No & 1,193 & 66.9 & 64.3 to 69.5 \\
\hline Yes & 412 & 23.0 & 20.8 to 25.2 \\
\hline Missing & 172 & 10.1 & 8.4 to 11.8 \\
\hline \multicolumn{4}{|l|}{ Radiation } \\
\hline No & 1,160 & 65.3 & 62.8 to 67.9 \\
\hline Yes & 445 & 24.6 & 22.2 to 26.9 \\
\hline Missing & 172 & 10.1 & 8.4 to 11.8 \\
\hline \multicolumn{4}{|l|}{ Hormonal treatment } \\
\hline No & 1,492 & 83.4 & 81.4 to 85.5 \\
\hline Yes & 113 & 6.4 & 5.1 to 7.8 \\
\hline Missing & 172 & 10.1 & 8.4 to 11.8 \\
\hline \multicolumn{4}{|l|}{ Currently cancer free } \\
\hline Yes & 1,358 & 76.1 & 73.9 to 78.4 \\
\hline No & 222 & 12.4 & 10.7 to 14.1 \\
\hline Missing & 197 & 11.5 & 9.7 to 13.3 \\
\hline \multicolumn{4}{|l|}{$\begin{array}{l}\text { History of research study/clinical trial } \\
\text { participation }\end{array}$} \\
\hline No & 1,631 & 81.3 & 79.1 to 83.4 \\
\hline Yes & 146 & 8.1 & 6.5 to 9.8 \\
\hline Missing & 181 & 10.6 & 8.9 to 12.3 \\
\hline \multicolumn{4}{|l|}{ No. of comorbidities } \\
\hline 0 & 394 & 23.8 & 21.6 to 26.0 \\
\hline 1 & 479 & 27.1 & 24.6 to 29.6 \\
\hline$\geq 2$ & 888 & 48.2 & 45.4 to 51.0 \\
\hline Missing & 16 & 0.9 & 0.4 to 1.5 \\
\hline
\end{tabular}

Abbreviation: GED, General Educational Development.

*Sample for age $\geq 80$ years: $n=99(4.7 \%)$.

thaw sample size for poverty status includes decimals because of multiple imputation procedures. 2010 Federal Poverty Status was $\$ 22,050$ for a family of four.

¥Includes lung, liver, pancreatic, stomach, and esophageal cancer

$\S$ Less prevalent cancers, all $\leq 4 \%$ of cancers.

"Last cancer site "unknown" was because of either multiple cancers diagnosed in the same calendar year or missing data on year of diagnosis for one or more reported cancers. An additional 54 patients were defined as missing on cancer site and time since diagnosis because of improbable combinations of cancer site and age at diagnosis.

release of IOM recommendations. Although discussion with survivors about the psychosocial effects of cancer is the recommended standard of care, ${ }^{27}$ many survivors might not need referral to formal psychological services. ${ }^{26}$ However, little is known about which survivors desire PCSG but experience potentially modifiable barriers (eg, lack of availability, lack of knowledge) to receipt of such care.

To enhance our understanding of current psychosocial care for cancer survivors on a national level and to benchmark the success of 
efforts to improve psychosocial care according to IOM recommendations, this study aimed to provide population-based prevalence estimates of health care provider discussions about cancer-related emotional and social concerns; characterize survivors who reported having a provider discussion, PCSG participation, and barriers to PCSG; and test the association between receipt of psychosocial services and satisfaction with how cancer-related emotional and social needs were met.

\section{PATIENTS AND METHODS}

\section{Data Source}

This study is based on data from the 2010 National Health Interview Survey (NHIS), ${ }^{28}$ an in-person, nationwide survey conducted by the National Center for Health Statistics (NCHS) of the Centers for Disease Control and Prevention (CDC) to track health-related trends in the United States. In 2010, NHIS included a Cancer Control Supplement developed and cosponsored by the National Cancer Institute (NCI) and the CDC. NHIS uses a complex, multistage sampling framework that involves clustering and stratification to derive a representative sample of the civilian, noninstitutionalized population; blacks, Hispanics, and Asians are oversampled. Data are collected through household interviews by trained census workers who use computer-assisted personal interviewing. Adults in the home at the time of the interview were invited to complete the Family Core component of the survey. One adult per household was randomly chosen to complete the Sample Adult Questionnaire, which in 2010 included the Cancer Control Supplement. The 2010 interviewed sample included 34,329 households containing 27,157 adults who completed the Sample Adult Questionnaire. For the Sample Adult component of the 2010 survey, the conditional response rate (given that household response occurred) was $77.3 \%$ of sample adults; the final response rate (accounting for household nonresponse) was $60.8 \%$. In the 2010 NHIS, 2,333 sample adults reported a cancer history. The current analytic sample $(\mathrm{N}=1,777)$ excluded those who reported exclusively nonmelanoma or unknown skin cancers $(\mathrm{n}=494)$, those who did not answer questions about cancer type $(\mathrm{n}=17)$, and those who reported exclusively cancer(s) diagnosed at age $\leq 21$ years $(\mathrm{n}=45$, due to differences in treatment settings for childhood/ adolescent cancer).

\section{Measures}

Sociodemographics and comorbid conditions. Age, sex, race/ethnicity, marital status, education, income (percent of the poverty index by using NHIS imputed data files), ${ }^{29}$ and health insurance status (related to the time of interview rather than time of cancer diagnosis/treatment) were obtained from the Family Core Survey. Education rather than income was used as a predictor in multivariable models because of high collinearity. Census region was obtained from the Sample Adult file. Comorbidity burden was defined by the sum of self-reported comorbid conditions ever diagnosed (hypertension, heart disease, stroke, diabetes, lung disease, arthritis) by using definitions from previous NHIS research ${ }^{30,31}$ plus arthritis because of its impact on psychosocial functioning. ${ }^{32}$

Cancer characteristics. Site and date of all cancers were drawn from the Cancer Control Supplement. We used the most recent cancer site because available treatment data relate to only the most recent cancer. We grouped short-survival cancers with a relative 5-year survival of less than 25\% (esophagus, liver, lung, pancreas, and stomach). ${ }^{30}$ We considered age at diagnosis, time since diagnosis, and cancer site to be missing for survivors who reported extremely unlikely combinations of cancer sites and corresponding ages (eg, prostate cancer at age of $3 ; \mathrm{n}=54) .{ }^{30}$ Survivors self-reported current cancer status (cancer free $v$ not), history of recurrence, treatment timing, treatment history for the most recent cancer (surgery, radiation, chemotherapy, or hormonal treatments), and past participation in a cancer-related research study/ clinical trial. Because the number of cancer episodes could be related to psychosocial care receipt, we created one indicator of cancer recurrence and/or multiple cancers.
Receipt of psychosocial services. As part of the Cancer Control Supplement, survivors were asked, "After you were diagnosed with cancer, did your doctor, nurse, or other health professional talk with you about how cancer may affect your emotions or your relationships with other people?" Survivors reported whether they received professional counseling or joined a support group (PCSG) after cancer was diagnosed to help cope and the main reason for nonuse where relevant ("I didn't know these services were available"/“I didn't want it"/"I didn't think I needed it"/“I couldn't afford it"/"Some other reason"). Participants were asked to specify "other" reasons. We categorized responses (including free-text responses) into barriers (eg, wasn't available, couldn't afford, transportation difficulties) and nonbarriers (eg, didn't want or need these services, adequate support from other sources). Finally, respondents reported their satisfaction with how health care providers met their cancer-related emotional/social needs (very satisfied/somewhat satisfied/not satisfied; recoded as "very satisfied" v "less than very satisfied").

\section{Data Analysis}

STATA 11.2 (STATA, College Station, TX) survey procedures were used to incorporate sampling weights and account for the complex sampling design of NHIS. We calculated national estimates for the number of cancer survivors not reporting receipt of psychosocial services by multiplying the percentage of survivors not reporting services by the sum of the population weights.

Multivariable logistic regression models were used to test factors associated with receipt of provider discussion and use of PCSG. To balance parsimony and inclusiveness, predictors (sociodemographic, cancer characteristics, cancer treatment, research study/clinical trial participation) were included in adjusted models when associated with receipt of services in bivariate tests $(P<.2)$. Similar methods were used to model satisfaction except that receipt of services (provider discussion and/or use of PCSG $v$ neither) was included in the model. Bivariate logistic regression models were used to test factors associated with barriers to use of PCSGs (a Bonferroni correction controlled the family-wise error rate, $\alpha=.0028$ ) and the association between provider discussion and use of PCSG. Estimates shown meet the NCHS standard of having relative SEs of $\leq 30 \% .{ }^{33}$

\section{RESULTS}

\section{Study Sample}

The analytic sample included 1,777 survivors. Survivors tended to be age $\geq 50$ years $(61.2 \%)$, female $(57.8 \%)$, and non-Hispanic white $(83.0 \%) ; 36.7 \%$ of survivors were diagnosed more than 10 years ago (Table 1). The most common cancer sites were breast (20.1\%),

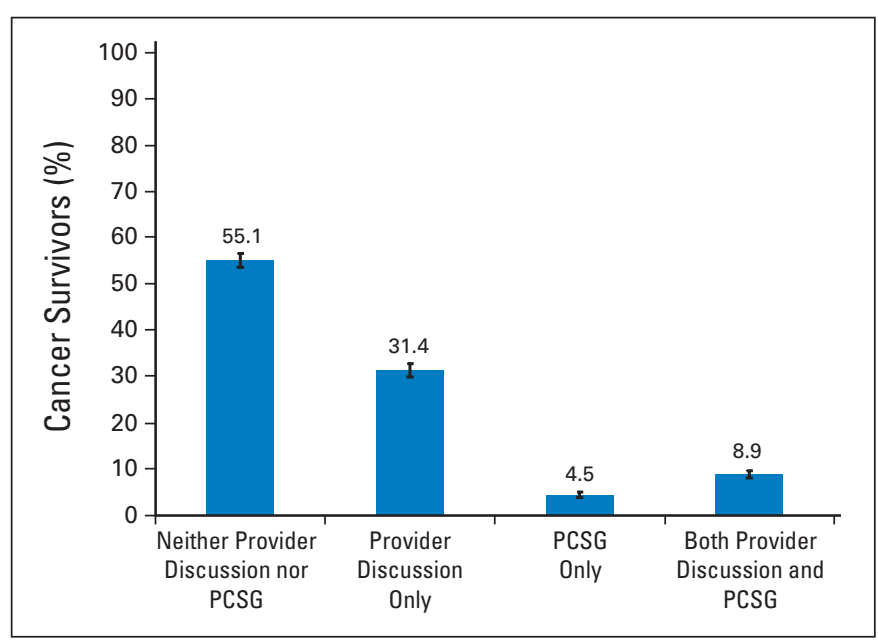

Fig 1. Receipt of psychosocial care among cancer survivors. Weighted percent and $95 \% \mathrm{Cl}$ (error bars). PCSG, professional counseling or support groups. 
Table 2. Factors Associated With Having a Discussion With Health Care Provider(s) About Emotional and Social Concerns After Cancer

\begin{tabular}{|c|c|c|c|c|c|c|c|c|}
\hline \multirow[b]{2}{*}{ Factor } & \multicolumn{3}{|c|}{ Unadjusted Models } & \multicolumn{3}{|c|}{$\begin{array}{l}\text { Mutivariable Model* } \\
\qquad(\mathrm{N}=1,436)\end{array}$} & \multirow[b]{2}{*}{ Wald $f$} & \multirow[b]{2}{*}{$P$} \\
\hline & $\begin{array}{c}\text { Weighted \% } \\
\text { With Discussion }\end{array}$ & $95 \% \mathrm{Cl}$ & $P$ & $\begin{array}{l}\text { Adjusted } \\
\text { OR }\end{array}$ & $95 \% \mathrm{Cl}$ & $P$ & & \\
\hline$\leq 39$ & 37.9 & 31.1 to 44.7 & & & & & & \\
\hline $40-49$ & 43.4 & 35.9 to 50.9 & & & & & & \\
\hline $50-64$ & 42.8 & 37.4 to 48.1 & & & & & & \\
\hline Male & 39.8 & 35.3 to 44.4 & & & & & & \\
\hline Female & 40.6 & 36.9 to 44.3 & & & & & & \\
\hline Race/ethnicity & & & $<.001$ & & & & 6.29 & $<.001$ \\
\hline Non-Hispanic white & 38.2 & 34.9 to 41.6 & & Ref & & & & \\
\hline Non-Hispanic black & 57.6 & 49.8 to 65.5 & & 2.46 & 1.64 to 3.71 & $<.001$ & & \\
\hline Hispanic & 42.3 & 32.7 to 51.9 & & 1.11 & 0.70 to 1.76 & .656 & & \\
\hline Education & & & .284 & & & & & \\
\hline$<$ High school & 37.7 & 30.4 to 45.1 & & & & & & \\
\hline High school or GED & 41.1 & 35.8 to 46.4 & & & & & & \\
\hline Some college or associate's degree & 43.8 & 38.7 to 48.9 & & & & & & \\
\hline Bachelor's degree or higher & 36.9 & 30.6 to 43.1 & & & & & & \\
\hline Health insurance status & & & .355 & & & & & \\
\hline Yes & 40.7 & 37.5 to 43.9 & & & & & & \\
\hline No & 33.8 & 24.8 to 42.9 & & & & & & \\
\hline Unknown & 42.2 & 30.4 to 54.1 & & & & & & \\
\hline Region & & & .990 & & & & & \\
\hline Northeast & 39.1 & 30.4 to 47.8 & & & & & & \\
\hline Midwest & 40.1 & 34.4 to 45.9 & & & & & & \\
\hline Short survival & 48.4 & 36.8 to 60.0 & & 0.90 & 0.51 to 1.59 & .703 & & \\
\hline Other & 31.9 & 26.6 to 37.2 & & 0.56 & 0.39 to 0.80 & .002 & & \\
\hline Recurrence or multiple cancers & & & .114 & & & & & \\
\hline No & 39.1 & 35.9 to 42.3 & & Ref & & & & \\
\hline Yes & 44.9 & 38.1 to 51.6 & & 1.27 & 0.87 to 1.85 & .218 & & \\
\hline Time since most recent cancer diagnosis, years & & & .161 & & & & 0.71 & .549 \\
\hline$<1$ & 39.9 & 29.3 to 50.4 & & Ref & & & & \\
\hline 1 to 5 & 44.1 & 39.3 to 48.8 & & 1.16 & 0.69 to 1.97 & .571 & & \\
\hline 6 to 9 & 40.2 & 32.8 to 47.5 & & 0.99 & 0.55 to 1.81 & .983 & & \\
\hline$\geq 10$ & 36.8 & 32.2 to 41.4 & & 0.94 & 0.54 to 1.63 & .814 & & \\
\hline Treatment timing & & & .001 & & & & 2.21 & .127 \\
\hline No recent treatment & 38.7 & 35.3 to 42.1 & & Ref & & & & \\
\hline Recent treatment (last 12 months) & 38.6 & 30.3 to 46.9 & & 0.94 & 0.60 to 1.46 & .768 & & \\
\hline Current treatment & 62.2 & 51.5 to 72.9 & & 1.79 & 0.97 to 3.33 & .064 & & \\
\hline Surgery & & & .039 & & & & & \\
\hline No & 45.0 & 39.7 to 50.3 & & Ref & & & & \\
\hline Yes & 38.2 & 34.7 to 41.8 & & 1.04 & 0.78 to 1.41 & .772 & & \\
\hline & (col & inued on follov & ing page) & & & & & \\
\hline
\end{tabular}




\begin{tabular}{|c|c|c|c|c|c|c|c|c|}
\hline \multirow[b]{2}{*}{ Factor } & \multicolumn{3}{|c|}{ Unadjusted Models } & \multicolumn{3}{|c|}{$\begin{array}{l}\text { Mutivariable Model* } \\
\qquad(\mathrm{N}=1,436)\end{array}$} & \multirow[b]{2}{*}{ Wald $f$} & \multirow[b]{2}{*}{$P$} \\
\hline & $\begin{array}{l}\text { Weighted \% } \\
\text { With Discussion }\end{array}$ & $95 \% \mathrm{Cl}$ & $P$ & $\begin{array}{l}\text { Adjusted } \\
\text { OR }\end{array}$ & $95 \% \mathrm{Cl}$ & $P$ & & \\
\hline CChemotherapy & & & $<.001$ & & & & & \\
\hline No & 34.6 & 31.4 to 37.9 & & Ref & & & & \\
\hline Yes & 56.8 & 50.9 to 62.7 & & 1.67 & 1.19 to 2.34 & .003 & & \\
\hline Radiation & & & .001 & & & & & \\
\hline No & 37.1 & 33.7 to 40.5 & & Ref & & & & \\
\hline Yes & 48.8 & 42.9 to 54.7 & & 1.26 & 0.92 to 1.72 & .156 & & \\
\hline Hormonal treatment & & & .734 & & & & & \\
\hline No & 40.5 & 37.4 to 43.5 & & & & & & \\
\hline Yes & 38.6 & 27.8 to 49.3 & & & & & & \\
\hline Currently cancer free & & & . 026 & & & & & \\
\hline Yes & 38.8 & 35.7 to 42.0 & & Ref & & & & \\
\hline No & 48.7 & 40.3 to 57.2 & & 0.96 & 0.63 to 1.46 & .843 & & \\
\hline $\begin{array}{l}\text { History of research study/clinical trial } \\
\text { participation }\end{array}$ & & & $<.001$ & & & & & \\
\hline No & 37.8 & 34.8 to 40.9 & & Ref & & & & \\
\hline Yes & 65.3 & 55.5 to 75.2 & & 2.18 & 1.35 to 3.51 & .001 & & \\
\hline No. of comorbidities & & & .489 & & & & & \\
\hline 0 & 43.5 & 37.5 to 49.4 & & & & & & \\
\hline 1 & 39.0 & 33.0 to 44.9 & & & & & & \\
\hline$\geq 2$ & 39.8 & 35.8 to 43.9 & & & & & & \\
\hline
\end{tabular}

prostate (15.5\%), and melanoma (10.1\%). Survivors excluded from any analyses due to missing data on provider discussion, use of PCSG, and/or satisfaction $(\mathrm{n}=213,12.0 \%)$ or covariates $(\mathrm{n}=142 ; 8.0 \%)$ were similar to those with complete data on age, sex, race/ethnicity, and region (all $P>.05)$.

\section{Receipt of Psychosocial Services}

More than half the survivors who responded about psychosocial care $(55.1 \%)$ reported neither provider discussion nor use of PCSG (Fig 1), which represents approximately 6,984,223 survivors in the United States (95\% CI, 6,612,725 to 7,355,723). Only $40.2 \%$ of survivors ( $95 \% \mathrm{CI}, 37.3 \%$ to $43.2 \%$ ) reported a provider discussion with or without PCSG. We estimate that 7,596,450 survivors in the United States (95\% CI, 7,221,536 to 7,971,365) did not discuss how cancer might affect psychosocial functioning with health care providers.

\section{Factors Associated With Provider Discussion}

Non-Hispanic blacks ( $v$ non-Hispanic whites), married survivors, survivors treated with chemotherapy, and past research study participants were more likely to report a provider discussion (all $P<.01$; Table 2). Survivors of prostate and other cancers were less likely than breast cancer survivors to report a discussion.

\section{Factors Associated With PCSG Use and Barriers to Use}

Survivors age 40 to 49 years ( $v \leq 39$ years), Hispanics ( $v$ nonHispanic whites), survivors treated with radiation, and past research study participants were more likely (although survivors diagnosed more than 6 years ago were less likely) to report PCSG use (all $P<.05$; Table 3). Survivors of melanoma and other cancers were less likely than breast cancer survivors to report PCSG use. Only 18.3\% (95\% CI, $15.9 \%$ to $20.7 \%$ ) of the reasons for nonuse of PCSG were considered barriers; most survivors indicated that they did not want or need PCSG $(73.2 \%)$ or that they had adequate support from other sources (3.6\%). The primary barrier was lack of knowledge about or unavailability of services ( $92.9 \%$ of barriers; $95 \%$ CI, $89.6 \%$ to $96.2 \%$ ). Fewer survivors ( $<10 \%$ of those with barriers) indicated other barriers (couldn't afford the services, transportation limitations, distance from the services, language barriers, or social stigma). Survivors age $\leq 39$ years ( $v$ age 50 to 64 years), those with less than high school education ( $v$ at least some college), those without insurance ( $v$ any insurance), and survivors $\geq 10$ years postdiagnosis ( $v<1$ year) were more likely to report barriers to PCSG participation (all $P<.001$ ). Finally, provider discussions were associated with PCSG use: $22.0 \%$ versus 7.6\% of survivors with and without a provider discussion, respectively, reported PCSG use $(P<.001)$.

\section{Satisfaction With How Needs Were Met by Health Care Providers}

Overall, most survivors (74.9\%; 95\% CI, $72.3 \%$ to $77.5 \%$ ) were very satisfied with how their emotional and social needs were met. Survivors who reported provider discussion and/or PCSG use were more likely to be "very satisfied" than those who reported neither service (odds ratio, $2.40 ; 95 \% \mathrm{CI}, 1.72$ to $3.35 ; P<.001$ ).

\section{DISCUSSION}

This study provides population-based estimates of psychosocial care for cancer survivors consistent with IOM recommendations. ${ }^{24} \mathrm{Al}$ though clinical and scientific attention to psychosocial survivorship 


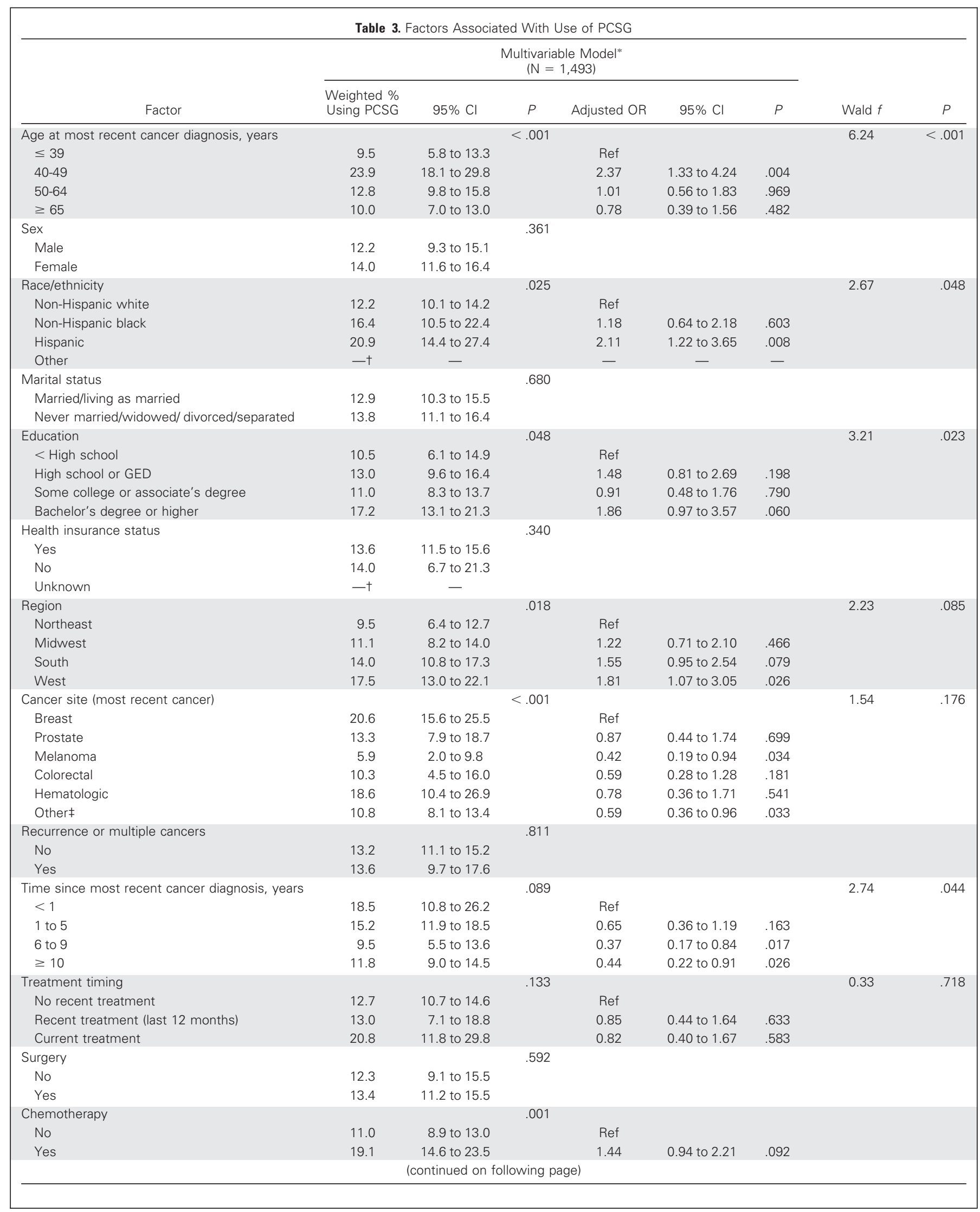




\begin{tabular}{|c|c|c|c|c|c|c|c|c|}
\hline \multirow[b]{2}{*}{ Factor } & \multicolumn{6}{|c|}{$\begin{array}{l}\text { Multivariable Model* } \\
\qquad(\mathrm{N}=1,493)\end{array}$} & \multirow[b]{2}{*}{ Wald $f$} & \multirow[b]{2}{*}{$P$} \\
\hline & $\begin{array}{l}\text { Welghted \% } \\
\text { Using PCSG }\end{array}$ & $95 \% \mathrm{Cl}$ & $P$ & Adjusted OR & $95 \% \mathrm{Cl}$ & $P$ & & \\
\hline Radiation & & & $<.001$ & & & & & \\
\hline No & 10.7 & 9.0 to 12.4 & & Ref & & & & \\
\hline Yes & 19.3 & 14.9 to 23.6 & & 1.62 & 1.06 to 2.48 & .025 & & \\
\hline Hormonal treatment & & & .105 & & & & & \\
\hline No & 12.6 & 10.8 to 14.3 & & Ref & & & & \\
\hline Yes & 19.4 & 10.0 to 28.7 & & 0.84 & 0.37 to 1.92 & .684 & & \\
\hline Currently cancer free & & & .260 & & & & & \\
\hline Yes & 12.8 & 10.9 to 14.8 & & & & & & \\
\hline No & 15.9 & 10.6 to 21.3 & & & & & & \\
\hline $\begin{array}{l}\text { History of research study/clinical trial } \\
\text { participation }\end{array}$ & & & $<.001$ & & & & & \\
\hline No & 11.4 & 9.7 to 13.2 & & Ref & & & & \\
\hline Yes & 30.1 & 22.0 to 38.2 & & 2.85 & 1.77 to 4.58 & $<.001$ & & \\
\hline No. of comorbidities & & & .445 & & & & & \\
\hline 0 & 13.3 & 9.1 to 17.5 & & & & & & \\
\hline 1 & 15.0 & 11.1 to 18.8 & & & & & & \\
\hline$\geq 2$ & 12.0 & 9.6 to 14.4 & & & & & & \\
\hline
\end{tabular}

care is increasing, ${ }^{34}$ to the best of our knowledge, this is the first study to provide population-based data regarding health care provider discussions with survivors about psychosocial concerns after cancer. Less than half the survivors reported having such a discussion with providers, even among those diagnosed after the release of IOM recommendations. Moreover, many survivors reported receipt of neither provider discussion nor PCSG, representing nearly 7 million US cancer survivors who recall no professional attention to their psychosocial needs after cancer. There is much work to be done to provide cancer care "for the whole patient." 24

Discussions with providers regarding psychosocial concerns after cancer can serve multiple purposes, including enhancing communication between providers, survivors, and their families about the importance of psychosocial needs, identifying otherwise undetected needs, and providing an opportunity for treatment or referral for psychosocial concerns. In our study, survivors who reported a provider discussion were more likely to use PCSG. Provider discussions may also promote satisfaction with how psychosocial needs are met (as in this study) and with cancer care overall, ${ }^{25,35}$ and may foster trusting, collaborative patient-provider relationships. ${ }^{36}$

The low prevalence of provider discussions about psychosocial concerns reflects missed opportunities for connecting survivors to appropriate interventions, particularly among vulnerable subgroups. Other than a positive association with history of chemotherapy, survivor-reported discussions generally did not correspond with known risk factors for psychosocial distress, including younger age, female sex, short-survival cancers, greater comorbidity burden, and lower education. ${ }^{1,37-41}$ In fact, unmarried survivors, who are at risk for less support and greater distress ${ }^{38}$ were less likely to report provider discussions. The higher proportion of non-Hispanic blacks who recalled a provider discussion compared with non-Hispanic whites may be attributable to greater psychological needs, ${ }^{42,43}$ an increased likelihood relative to whites of blacks attending an NCI-designated cancer center, ${ }^{44}$ the role black pastors (who may be perceived as health care providers) play in promoting health, ${ }^{45}$ or cultural differences in response style. Future research should investigate the relationships between race/ethnicity and provider discussions about psychosocial issues to better understand factors that promote high-quality care for all racial/ethnic groups. In addition, because providers' confidence in their knowledge about adverse psychosocial events after cancer is associated with their involvement in assessment and treatment of psychological distress, ${ }^{46}$ the reduced likelihood that survivors with relatively uncommon cancers reported discussions may be indicative of lower provider familiarity with these cancers.

Consistent with earlier studies, survivors of rarer cancers and melanoma, survivors farther out from diagnosis, and younger and older adults compared with middle-age survivors ${ }^{26,47}$ were less likely to use PCSG. These patterns appear stable despite growing acceptance of ${ }^{48}$ and demand for ${ }^{49}$ mental health services in the United States. In contrast to earlier work, ${ }^{26,47}$ Hispanics were more likely than nonHispanic whites to report PCSG use. Our finding may reflect changes in the perceived acceptability of psychosocial services among Hispanics or counseling from sources less frequently accessed by nonHispanic white survivors (eg, pastoral counseling). ${ }^{50}$

Approximately one in six survivors who did not use PCSG indicated that they did not know about or lacked access to these services. Although most comprehensive cancer centers and community cancer centers now offer PCSG, many institutions have fewer than three psychosocial providers, ${ }^{51}$ which may be insufficient to meet survivors' needs. One study suggests that only $10 \%$ of survivors report that support groups were recommended by their physician. ${ }^{47}$ Thus, psychosocial care delivery may be improved by ensuring that survivors 
are made aware of the services available at their treatment facility, in the community, and/or online. Efforts to connect survivors with appropriate psychosocial care should focus on vulnerable subgroups (eg, survivors who are younger, less educated, and without insurance and who are more years postdiagnosis).

Past participation in cancer-related research studies/clinical trials was positively associated with provider discussion and PCSG use. Perhaps study participation is a proxy for being treated in a comprehensive cancer center with better availability of research studies and psychosocial care. Alternatively, survivors who volunteer for cancerrelated research may be more "activated" for participation in healthrelated activities ${ }^{52}$ or have motivations driving participation in both research and psychosocial care (eg, reassurance, interaction with concerned people). ${ }^{53}$ Finally, psychosocial health may be discussed as part of cancer research, independent of clinical care. Future studies should clarify the role of participation in cancer-related research for psychosocial care.

Health care providers face many demands with inadequate time to address all aspects of survivorship. ${ }^{54}$ However, responsibility for discussions about the psychosocial consequences of cancer and appropriate referral does not belong exclusively to oncologists. Many primary care physicians feel that discussing survivors' psychosocial needs is within their purview. ${ }^{46}$ Both primary care physicians and other oncology team members, including nurses and nonphysician providers, can play important roles in addressing psychosocial needs. ${ }^{55} \mathrm{Co}-$ ordination within and between provider teams is essential for ensuring that psychosocial services meet patient needs without overburdening providers or duplicating care. ${ }^{46}$

Standardized distress screening is recommended for all survivors at the time of cancer diagnosis and at important transition points along the cancer continuum (eg, completion of cancer treatment). ${ }^{27,56}$ This practice currently occurs on a limited basis ${ }^{51,57}$ but will be required for accreditation by the American College of Surgeons Commission on Cancer starting in 2015. Distress screening can prompt dialogue between providers and survivors about psychosocial needs and inform actions toward meeting those needs. However, brief discussions about psychosocial issues are needed, even when survivors do not screen positive for distress, and despite our finding that many survivors were already satisfied with how psychosocial needs are met. Such discussions provide invaluable opportunities to facilitate communication about psychosocial needs, as recommended by the $\mathrm{IOM},{ }^{24}$ to gauge interest in psychosocial services, and to lay the groundwork for addressing future needs.

Limitations of this study include self-reported data that may underestimate the prevalence of provider discussions/PCSG due to recall bias. Recall of provider discussion was independent of time since diagnosis, while recall of PCSG use was higher among those diagnosed more recently. Nevertheless, useful interventions were likely to be more memorable than less effective ones. PCSG use may not have been reported if respondents did not conceptualize the purpose of such interventions (eg, managing physical symptoms) as helping with coping. As is common in large epidemiologic studies, receipt of psy- chosocial services was assessed by using single items; however, this study offers a rare opportunity to provide population-based estimates of psychosocial care. The current survey did not assess who initiated discussions (eg, providers, survivors, caregivers). We could not determine the type of provider(s) involved in discussions or delivering PCSG, when psychosocial services were received, where cancer treatment or psychosocial services were received (eg, comprehensive cancer center, community cancer center), or whether survivors used professional counseling, support groups, or both. Future research should tease apart the role of survivors, different types of providers, and care settings in psychosocial care. Healthier survivors may have been more likely to participate with NHIS or to provide complete data, but survivors with missing data reported characteristics similar to those with complete data. Some questions related to the time of interview rather than cancer diagnosis/treatment. Given the cross-sectional nature of NHIS, causal inferences cannot be made about associations between receipt of services and survivor satisfaction or quality of life. Finally, the IOM made other recommendations regarding psychosocial care (eg, coordination of biomedical and psychosocial care and systematically following up on and adjusting treatment plans) that were not assessed in NHIS that merit exploration in future studies.

This study provides unique information about receipt of psychosocial services on a national level. More than half of survivors in the US reported not having had a discussion with their health care providers about psychosocial concerns after cancer, reflecting a missed opportunity to connect survivors with appropriate care. These data provide benchmarks to measure improvements in psychosocial care delivery and inform efforts to increase the reach of psychosocial care. Because interventions targeting providers (eg, communication skills training $)^{25}$ are not uniformly successful in improving detection of distress ${ }^{58}$ and because cancer survivors can be trained to initiate conversations with providers about their symptoms, ${ }^{59}$ ultimately effective patient-provider communication regarding psychosocial concerns may be best facilitated by multilevel interventions. Future research using qualitative and quantitative methods to understand survivor, provider, and health system barriers to psychosocial care may illuminate ways to improve care delivery.

\section{AUTHORS' DISCLOSURES OF POTENTIAL CONFLICTS} OF INTEREST

The author(s) indicated no potential conflicts of interest.

\section{AUTHOR CONTRIBUTIONS}

Conception and design: All authors

Data analysis and interpretation: All authors

Manuscript writing: All authors

Final approval of manuscript: All authors

\section{REFERENCES}

1. Massie MJ: Prevalence of depression in patients with cancer. J Natl Cancer Inst Monogr 32: 57-71, 2004
2. Armes J, Crowe M, Colbourne L, et al: Patients' supportive care needs beyond the end of cancer treatment: A prospective, longitudinal survey. J Clin Oncol 27:6172-6179, 2009

3. Pardue SF, Fenton MV, Rounds LR: The social impact of cancer. Dimens Oncol Nurs 3:5-13, 1989
4. Mellon S, Northouse LL, Weiss LK: A population-based study of the quality of life of cancer survivors and their family caregivers. Cancer Nurs 29:120-131, 2006

5. Lobb EA, Joske D, Butow $P$, et al: When the safety net of treatment has been removed: Patients' 
unmet needs at the completion of treatment for haematological malignancies. Patient Educ Couns 77:103-108, 2009

6. McDowell ME, Occhipinti S, Ferguson M, et al: Predictors of change in unmet supportive care needs in cancer. Psychooncology 19:508-516, 2010

7. Hewitt M, Greenfield S, Stovall E (eds): From Cancer Patient to Cancer Survivor: Lost in Transition. Washington, DC, National Academies Press, 2005

8. Stark $D$, Kiely $M$, Smith $A$, et al: Anxiety disorders in cancer patients: Their nature, associations, and relation to quality of life. J Clin Oncol 20:3137-3148, 2002

9. Kroenke $\mathrm{K}$, Theobald $\mathrm{D}$, Wu J, et al: The association of depression and pain with healthrelated quality of life, disability, and health care use in cancer patients. J Pain Symptom Manage 40:327341,2010

10. Lim JW, Zebrack B: Different pathways in social support and quality of life between Korean American and Korean breast and gynecological cancer survivors. Qual Life Res 17:679-689, 2008

11. Ng DM, Jeffery RW: Relationships between perceived stress and health behaviors in a sample of working adults. Health Psychol 22:638-642, 2003

12. Torres SJ, Nowson CA: Relationship between stress, eating behavior, and obesity. Nutrition 23 : 887-894, 2007

13. Todd M: Daily processes in stress and smoking: Effects of negative events, nicotine dependence, and gender. Psychol Addict Behav 18:31-39, 2004

14. Alfano $\mathrm{CM}$, Day JM, Katz ML, et al: Exercise and dietary change after diagnosis and cancerrelated symptoms in long-term survivors of breast cancer: CALGB 79804. Psychooncology 18:128-133, 2009

15. Rogers LQ, McAuley E, Courneya KS, et al: Correlates of physical activity self-efficacy among breast cancer survivors. Am J Health Behav 32:594603, 2008

16. Chou AF, Stewart SL, Wild RC, et al: Social support and survival in young women with breast carcinoma. Psychooncology 21:125-133, 2012

17. Pinquart $M$, Duberstein PR: Depression and cancer mortality: A meta-analysis. Psychol Med 40: 1797-1810, 2010

18. Satin JR, Linden W, Phillips MJ: Depression as a predictor of disease progression and mortality in cancer patients: A meta-analysis. Cancer 115: 5349-5361, 2009

19. Giese-Davis J, Collie K, Rancourt KM, et al: Decrease in depression symptoms is associated with longer survival in patients with metastatic breast cancer: A secondary analysis. J Clin Oncol 29:413-420, 2011

20. Kroenke $\mathrm{CH}$, Kubzansky LD, Schernhammer $E S$, et al: Social networks, social support, and survival after breast cancer diagnosis. J Clin Oncol 24:1105-1111, 2006

21. Werner $A$, Stenner $C$, Schüz J: Patient versus clinician symptom reporting: How accurate is the detection of distress in the oncologic after-care? Psychooncology 21:818-826, 2012

22. Passik SD, Dugan W, McDonald MV, et al: Oncologists' recognition of depression in their patients with cancer. J Clin Oncol 16:1594-1600, 1998

23. Fallowfield $L$, Ratcliffe $D$, Jenkins $V$, et al: Psychiatric morbidity and its recognition by doctors in patients with cancer. $\mathrm{Br} \mathrm{J}$ Cancer 84:1011-1015, 2001

24. Adler NE, Page AE (eds): Cancer Care for the Whole Patient: Meeting Psychosocial Healthcare Needs. Washington, DC, National Academies Press, 2008

25. Hack TF, Degner LF, Parker PA, et al: The communication goals and needs of cancer patients: A review. Psychooncology 14:831-845, 2005

26. Hewitt M, Breen N, Devesa S: Cancer prevalence and survivorship issues: Analyses of the 1992 National Health Interview Survey. J Natl Cancer Inst 91:1480-1486, 1999

27. Jacobsen PB, Wagner LI: A new quality standard: The integration of psychosocial care into routine cancer care. J Clin Oncol 30:1154-1159, 2012

28. Centers for Disease Control and Prevention (CDC): National Health Interview Survey (NHIS). Atlanta, GA, Centers for Disease Control and Prevention, U.S. Department of Health and Human Services, 2011. http://www.cdc.gov/nchs/nhis.htm

29. National Center for Health Statistics (NCHS): Data File Documentation, National Health Interview Survey, 2010 (machine readable data file and documentation). Hyattsville, MD, National Center for Health Statistics, Centers for Disease Control and Prevention, 2011

30. Yabroff KR, Lawrence WF, Clauser $S$, et al: Burden of illness in cancer survivors: Findings from a population-based national sample. J Natl Cancer Inst 96:1322-1330, 2004

31. Pratt LA: Serious psychological distress, as measured by the K6, and mortality. Ann Epidemiol 19:202-209, 2009

32. Jakobsson U, Hallberg IR: Pain and quality of life among older people with rheumatoid arthritis and/or osteoarthritis: A literature review. J Clin Nurs 11:430-443, 2002

33. Ward B, Barnes P, Freeman G, et al: Early release of selected estimates based on data from the 2011 National Health Interview Survey. National Center for Health Statistics, 2012. http://www.cdc.gov/nchs/ nhis.htm

34. Jacobsen PB, Holland JC, Steensma DP: Caring for the whole patient: The science of psychosocial care. J Clin Oncol 30:1151-1153, 2012

35. Arora NK, Reeve BB, Hays RD, et al: Assessment of quality of cancer-related follow-up care from the cancer survivor's perspective. J Clin Oncol 29: 1280-1289, 2011

36. Arora NK, Street RL Jr, Epstein RM, et al: Facilitating patient-centered cancer communication: A road map. Patient Educ Couns 77:319-321, 2009

37. Parker PA, Baile WF, de Moor Cd, et al: Psychosocial and demographic predictors of quality of life in a large sample of cancer patients. Psychooncology 12:183-193, 2003

38. Schnoll RA, Knowles JC, Harlow L: Correlates of adjustment among cancer survivors. J Psychosoc Oncol 20:37-60, 2002

39. Schnoll RA, Harlow LL: Using disease-related and demographic variables to form cancer-distress risk groups. J Behav Med 24:57-74, 2001

40. Zebrack B, Hamilton R, Smith AW: Psychosocial outcomes and service use among young adults with cancer. Semin Oncol 36:468-477, 2009

41. Zebrack BJ, Yi J, Petersen L, et al: The impact of cancer and quality of life for long-term survivors. Psychooncology 17:891-900, 2008
42. Beckjord EB, Arora NK, McLaughlin W, et al: Health-related information needs in a large and diverse sample of adult cancer survivors: Implications for cancer care. J Cancer Surviv 2:179-189, 2008

43. Moadel AB, Morgan C, Dutcher J: Psychosocial needs assessment among an underserved, ethnically diverse cancer patient population. Cancer 109:446-454, 2007

44. Onega T, Duell EJ, Shi $X$, et al: Race versus place of service in mortality among Medicare beneficiaries with cancer. Cancer 116:2698-2706, 2010

45. Levin JS: Roles for the black pastor in preventive medicine. Pastoral Psychol 35:94-103, 1986

46. Forsythe LP, Alfano CM, Leach CR, et al: Who provides psychosocial follow-up care for posttreatment cancer survivors? A survey of medical oncologists and primary care physicians. J Clin Oncol 30:2897-2905, 2012

47. Owen JE, Goldstein MS, Lee JH, et al: Use of health-related and cancer-specific support groups among adult cancer survivors. Cancer 109:25802589, 2007

48. Mojtabai R: Americans' attitudes toward mental health treatment seeking: 1990-2003. Psychiatr Serv 58:642-651, 2007

49. Zuvekas SH: Trends in mental health services use and spending, 1987-1996. Health Aff (Millwood) 20:214-224, 2001

50. Wang PS, Berglund PA, Kessler RC: Patterns and correlates of contacting clergy for mental disorders in the United States. Health Serv Res 38:647673, 2003

51. Deshields T, Zebrack B, Kennedy V: The state of psychosocial services in cancer care in the United States. Psychooncology [epub ahead of print on February 21, 2012]

52. Wagner EH, Glasgow RE, Davis C, et al: Quality improvement in chronic illness care: A collaborative approach. Jt Comm J Qual Improv 27:6380, 2001

53. Mattson ME, Curb JD, McArdle R: Participation in a clinical trial: The patients' point of view. Control Clin Trials 6:156-167, 1985

54. Bober SL, Recklitis CJ, Campbell EG, et al: Caring for cancer survivors: A survey of primary care physicians. Cancer 115:4409-4418, 2009

55. McCabe MS: Models of survivorship care, in Miller K (ed): Excellent Care for Cancer Survivors: A Guide to Fully Meet Their Needs in Medical Offices and in the Community. Santa Barbara, CA, Praeger, 2012

56. National Comprehensive Cancer Network (NCCN): NCCN Clinical Practice Guidelines in Oncology: Distress Management v2.2009. Fort Washington, PA, National Comprehensive Cancer Network (NCCN), 2009

57. Jacobsen PB, Ransom S: Implementation of NCCN distress management guidelines by member institutions. J Natl Compr Canc Netw 5:99-103, 2007

58. Merckaert I, Libert Y, Delvaux N, et al: Factors that influence physicians' detection of distress in patients with cancer: Can a communication skills training program improve physicians' detection? Cancer 104:411-421, 2005

59. Street RL Jr, Slee C, Kalauokalani DK, et al: Improving physician-patient communication about cancer pain with a tailored education-coaching intervention. Patient Educ Couns 80:42-47, 2010 
Forsythe et al

Acknowledgment

We thank Chris Zeruto (Information Management Services, Rockville, MD) for his assistance with the statistical analyses. 